\title{
Submucosal injection solution for gastrointestinal tract endoscopic mucosal resection and endoscopic submucosal dissection
}

\author{
Toshio Uraoka' \\ Yutaka Saito ${ }^{2}$ \\ Kazuhide Yamamoto' \\ Takahiro Fujii ${ }^{3}$ \\ 'Department of Gastroenterology \\ and Hepatology, Okayama University \\ Graduate School of Medicine, \\ Dentistry and Pharmaceutical \\ Sciences, Okayama, Japan; ${ }^{2}$ Division of \\ Endoscopy, National Cancer Center \\ Hospital, Tokyo, Japan; ${ }^{3}$ TF Clinic, \\ Tokyo, Japan
}

\begin{abstract}
Endoscopic mucosal resection (EMR) and endoscopic submucosal dissection (ESD) have provided new alternatives for minimally invasive treatment of gastrointestinal adenomas and early-stage cancers that involve a minimum risk of lymph-node metastasis. The use of submucosal injections is essential to the success of these endoscopic resection techniques. The "ideal" submucosal injection solution should provide a sufficiently high submucosal fluid cushion for safe and effective EMRs and ESDs while also preserving lesion tissue for accurate histopathological assessment. In the past, normal saline (NS) solution was commonly used for this purpose, but it is difficult to achieve the proper submucosal elevation and maintain the desired height with NS. Therefore, other safe and effective facilitative submucosal injection solutions have been developed that also take into account relevant cost-benefit considerations. This review examines recent advances in the development of effective submucosal injection solutions for use during endoscopic resections.
\end{abstract}

Keywords: submucosal injection solution, endoscopic mucosal resection (EMR), endoscopic submucosal dissection (ESD), gastrointestinal tract

\section{Introduction}

Endoscopic mucosal resection (EMR) is a minimally invasive technique which is safe, relatively simple, and effective in the curative treatment of early cancers with an extremely low risk of lymph-node metastasis and for the removal of adenomas as precursors to cancer in the gastrointestinal region. EMR also plays an important role in the assessment of resected specimens for accurate pathological staging (Kudo 1993; Soetikno et al 2003).

In contrast to polypectomy, EMR involves the lifting up of a lesion from the muscular layer by injecting a fluid agent, commonly normal saline (NS) solution, into the submucosal layer. Because it is difficult to achieve the necessary submucosal elevation and then maintain the desired height with NS, various submucosal injection solutions have been newly developed for safer, easier to use, and more effective EMRs (Torii et al 1995; Yamamoto et al 1999, 2002, 2003; Conio et al 2002; Sumiyoshi et al 2002; Feitoza et al 2003; Fujishiro et al 2004a, 2004b, 2005, 2006; Lee et al 2004, 2006; Rajan et al 2004; Uraoka et al 2005; Jin Hyun et al 2006; Katsinelos et al 2006; Yamasaki et al 2006; Ishizuka et al 2007).

This review examines recent advances in the development of effective submucosal injection solutions for use during endoscopic resections.

\section{Endoscopic resection techniques EMR}

EMR is a less invasive curative treatment for gastrointestinal adenomas and early-stage cancers that involve a minimum risk of lymph-node metastasis. It is also useful 
for obtaining specimens for accurate histopathological staging to determine the risk of lymph-node metastasis. EMR completely removes the affected mucosa by excising through the middle or deeper portion of the gut wall submucosa. Various EMR techniques have been described and four methods involving snare resection are commonly used: (1) the inject and cut method (Kudo 1993; Soetikno et al 2003; Uraoka et al 2005); (2) the inject, lift, and cut method (Karita et al 1991; Tada et al 1993); (3) cap-assisted EMR (EMRC) (Inoue et al 1993; Matsuzaki et al 2003); and (4) EMR with ligation (EMRL) (Suzuki et al 1999).

The inject and cut technique, also known as submucosal injection polypectomy, has become widely used in recent years because of its simplicity. The diseased mucosa is lifted up from the muscular layer by creating a submucosal fluid cushion, captured, strangulated using an electrosurgical snare, and then resected. However, injection into the thin submucosal layer is a delicate process, the injected solution tends to dissipate quickly, flat and depressed lesions are hard to capture with the snare compared with protruded lesions, and large or awkwardly located lesions can be difficult to remove.

The technical limitations of standard EMR techniques, therefore, often result in piecemeal resections, particularly in cases of large lesions or those in less accessible locations, leading to problems in correctly assessing the depth of tumor invasion and increasing the possibility of local recurrence. Consequently, en-bloc resections using this procedure are limited to lesions approximately $15-20 \mathrm{~mm}$ in size (Tanaka et al 2001; Uraoka et al 2005; Gotoda 2005).

\section{Endoscopic submucosal dissection}

Endoscopic submucosal dissection (ESD), a relatively new endoscopic resection procedure, was developed specifically for removing larger lesions (Ohkuwa et al 2001; Ono et al 2001; Yamamoto et al 2003; Gotoda 2005; Saito et al 2005, 2007; Fujishiro et al 2006; Uraoka et al 2007). Lesions are dissected directly along the submucosal layer using an electrosurgical knife, resulting in an en-bloc resection of even large lesions.

ESD has been predicted to replace conventional surgery in treating certain cancerous stages, but because it has a higher rate of perforation and bleeding complications than conventional EMR, a greater degree of endoscopic skill and experience is required than for EMR. Various submucosal injection solutions had previously been developed and shown to be satisfactory for use during EMR, but introduction of the lengthier ESD procedure required a longer-lasting solution to help identify the cutting line during dissection of the submucosal layer.

\section{Role of submucosal injection solution}

Various recently developed endoscopic techniques, submucosal injection solutions, and devices such as the electrosurgical snare, submucosal injection catheter, and endo-clip have made EMR safer, easier, and more effective (Yamano et al 2004; Taku et al 2007). The use of submucosal injection is essential for a successful EMR, as injection of fluid into the submucosa cushions and isolates the tissue just before capture of the target lesion with a snare, thereby reducing thermal injury and the risk of perforation and hemorrhage while also facilitating an en-bloc resection. The en-bloc resection, in turn, provides for more accurate histopathological assessment and reduces the risk of local recurrence after the EMR, as previously described (Ono et al 2001; Soetikno et al 2003).

Submucosal injection is considered to play an important role in the EMR procedure, and the "ideal" submucosal injection solution should be both long-lasting and produce a hemispheric shape to facilitate snaring. In addition, providing a sufficiently high submucosal elevation is important for safe submucosal cutting during the ESD procedure.

NS solution has been commonly used for this purpose, but it is difficult to produce the proper submucosal fluid cushion and maintain the desired height, particularly for flat elevated lesions, because of the rapid absorption of NS into the surrounding tissue (Yamamoto et al 1999; Conio et al 2002; Sumiyoshi et al 2002; Fujishiro et al 2004; Jin Hyun et al 2006; Katsinelos et al 2006; Lee et al 2006). Several studies, therefore, have compared various submucosal injection solutions by evaluating their ability to maintain mucosal elevation during EMR.

In general, hypertonic solutions create higher mucosal elevation than NS solution (Conio et al 2002; Fujishiro et al 2004, 2006; Katsinelos et al 2006). Solutions currently used besides NS for submucosal injections including hypertonic saline, hypertonic dextrose water (DW) (Katsinelos et al 2006), glycerol (Torii et al 1995; Sumiyoshi et al 2002; Uraoka et al 2005), and hyaluronic acid (HA) (Fujishiro et al 2004; Yamamoto et al 1999, 2002, 2003) are listed in Table 1. Submucosal injection solutions need to be evaluated not only for their lesion-lifting ability during EMR and ESD procedures, but they also must be safe, avoid histopathological tissue damage, and be of reasonable cost.

\section{Submucosal injection solutions}

Although NS solution is safe, inexpensive, and commonly used throughout the world, there are problems in achieving 
Table I Submucosal injection solutions for EMR/ESD

\begin{tabular}{|c|c|}
\hline $\begin{array}{l}\text { Normal Saline (NS) } \\
\text { Solution }\end{array}$ & $\begin{array}{l}\text { - Commonly used, but fluid cushion } \\
\text { not long-lasting }\end{array}$ \\
\hline Hypertonic Saline Solution & - Hypertonic solution \\
\hline Glycerol ${ }^{3,11,12}$ & $\begin{array}{l}\text { - Facilitates easier and safer EMR/ } \\
\text { ESD at low cost }\end{array}$ \\
\hline Dextrose Water (DW) ${ }^{10}$ & $\begin{array}{l}\text { - Cheaper hypertonic solution, } \\
\text { but likelihood of tissue damage } \\
\text { in concentrations } \geq 20 \%\end{array}$ \\
\hline Hyaluronic Acid $(\mathrm{HA})^{4-6,13,14}$ & $\begin{array}{l}\text { - Produces and maintains } \\
\text { long-lasting fluid cushion, but high } \\
\text { cost and limited availability }\end{array}$ \\
\hline Fibrinogen Mixture (FM) ${ }^{15,16}$ & $\begin{array}{l}\text { - High viscosity and reasonable } \\
\text { cost, but risk of virus transmission }\end{array}$ \\
\hline $\begin{array}{l}\text { Hydroxypropyl } \\
\text { Methylcellulose (HPMC) })^{17-19}\end{array}$ & $\begin{array}{l}\text { - Produces long-lasting fluid } \\
\text { cushion, inexpensive and readily } \\
\text { available, but detailed toxicity } \\
\text { testing necessary }\end{array}$ \\
\hline
\end{tabular}

Abbreviations: EMR, endoscopic mucosal resection; ESD, endoscopic submucosal resection.

a suitable submucosal elevation and then maintaining the desired height with NS. A better submucosal injection solution is needed, therefore, so that safer, easier, and more effective EMRs can be performed, and a number of alternatives have been developed recently in response to this need.

\section{Glycerol}

Glycerol (Glyceol ${ }^{\circledR}$, Chugai Pharmaceutical Co, Tokyo, Japan) is a hypertonic solution consisting of $10 \%$ glycerin and 5\% fructose in an NS solution that has been used intravenously to treat cerebral edema with no toxic systemic effects (Takeuchi et al 1989; Sakamaki et al 2003). Glycerol was first mentioned as a submucosal injection solution in a report on 24 early gastric cancer cases that were treated using the EMRC method; however, no investigation was carried out on the efficacy of this particular solution at that time (Torii et al 1995). Subsequently, we directed our attention to glycerol and carried out basic and clinical studies on its effectiveness as a submucosal injection solution (Sumiyoshi et al 2002; Uraoka et al 2005).

\section{Basic study}

In an in vitro study, the abilities were compared of glycerol and NS solution to maintain long-lasting submucosal elevation using fresh resected human colon specimens (Sumiyoshi et al 2002). Each solution was injected into the submucosal layer using a 23-gauge submucosal injection needle with a clear endoscopic attachment, $16 \mathrm{~mm}$ in diameter, to a submucosal elevation height of $5 \mathrm{~mm}$; 10 separate test solution submucosal injections were made in both the glycerol and NS groups. Submucosal elevations were observed from the lateral position and recorded using a measuring device $1,3,5,7$, and 10 minutes after injection. The glycerol group maintained a significantly longer-lasting submucosal elevation than the NS group (Figures 1 and 2) and the hemispheric shape produced by the glycerol solution facilitated snaring satisfactorily (Figure 2).

\section{Clinical study}

During the next stage, we examined clinically the efficacy of glycerol as a submucosal solution during EMR (Uraoka et al 2005). This study retrospectively compared the en-bloc resection and complete resection rates as well as the rates of associated complications for the EMR of large flat lesions, known as laterally spreading tumors (LSTs) (Saito et al 2001; Tanaka et al 2001; Uraoka et al 2005, 2006), in the colorectum when using glycerol or NS as the injecting solution. The en-bloc resection rate was $63.6 \%(70 / 110)$ in the glycerol group and $48.9 \%(55 / 113)$ in the NS group $(p=0.03)$ (Table 2$)$. Based on lesion size, there was no difference between the two groups for lesions $\geq 20 \mathrm{~mm}$, but the glycerol group had a higher en-bloc resection rate than the NS control group $(p<0.01)$ in LSTs measuring $10-19 \mathrm{~mm}$. LSTs $\geq 20 \mathrm{~mm}$ are technically more difficult to remove en bloc by conventional EMR techniques (Tanaka et al 2001; Gotoda 2005) and the use of glycerol did not improve the en-bloc resection rate for such lesions. The rate of associated complications such as perforations and delayed bleeding was similar in both groups. There were no problems involving histopathological tissue damage to the resected specimens due to the injection solution in either group. The use of glycerol was shown to safely increase enbloc resections in this study. Because glycerol is relatively inexpensive in Japan (US $\$ 0.01-0.02 / \mathrm{mL}$ ) and readily available, it is considered superior to NS for use as a submucosal injection solution for EMRs of colorectal tumors.

\section{Dextrose water}

Dextrose water (DW) is a hypertonic solution that produces a higher submucosal elevation than NS solution. DW is inexpensive and readily available, but Fujishiro and colleagues (2005) reported that possible histopathological tissue damage resulted when the dextrose concentration was $>15 \%$ in a comparison study of injection solutions consisting of just NS, DW with five different concentrations $(5 \%, 10 \%, 15 \%$, $30 \%$, and $40 \%$ ) of dextrose, glycerol, and HA using mini-pig stomachs. Considerable tissue damage was observed with DW at concentrations $\geq 20 \%$ which could adversely affect resected EMR specimens and ulcer healing. 


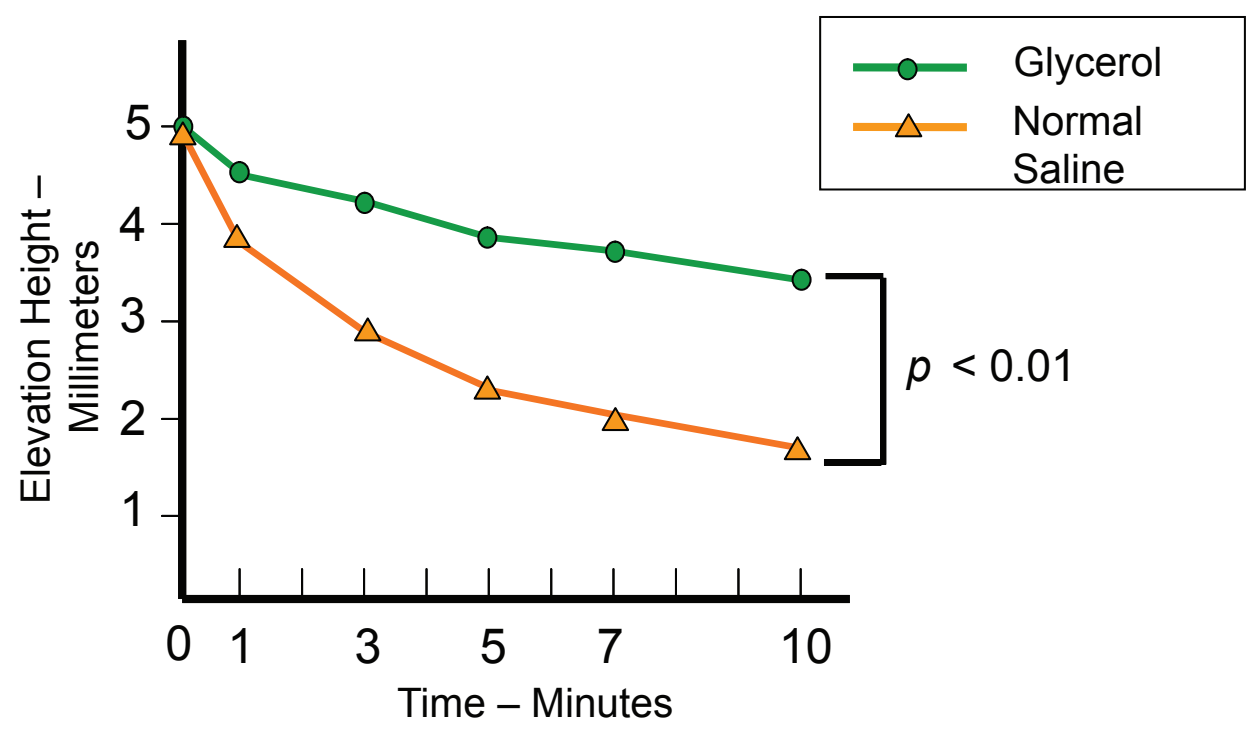

Figure I Chronological changes in submucosal elevations after injections of glycerol and normal saline (Sumiyoshi et al 2002). Glycerol maintained a significantly longer-lasting submucosal elevation than normal saline.

Clinical use of a 50\% DW plus epinephrine submucosal injection solution (Katsinelos et al 2006) has also been reported, but subsequent evidence of histopathological tissue damage raises a serious question about the suitability of DW. In fact, it has been used in the past as a sclerosing agent in esophageal varices (Yamamoto et al 1999). The histopathological predictive factor of lymph-node metastasis in early stage gastrointestinal cancer has been clarified so that accurate histopathological assessment is critical for determining the appropriate therapeutic strategies. Use of
Glycerol

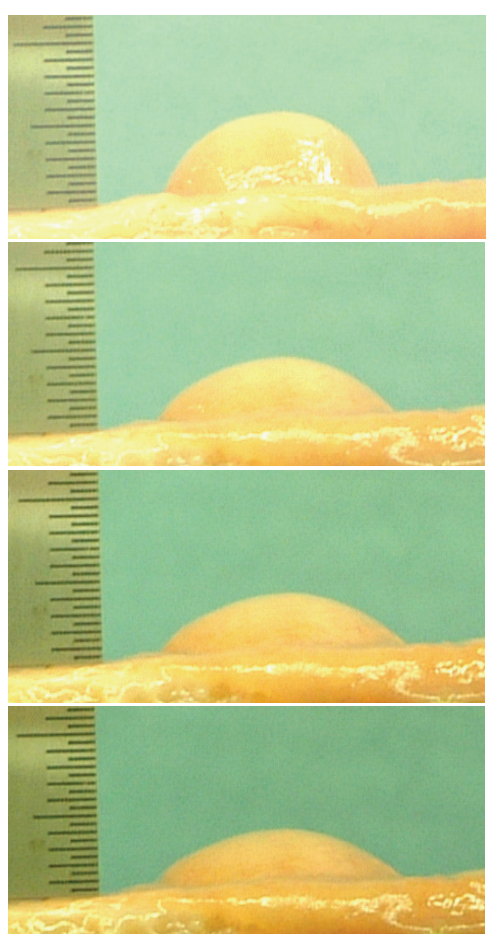

Normal Saline

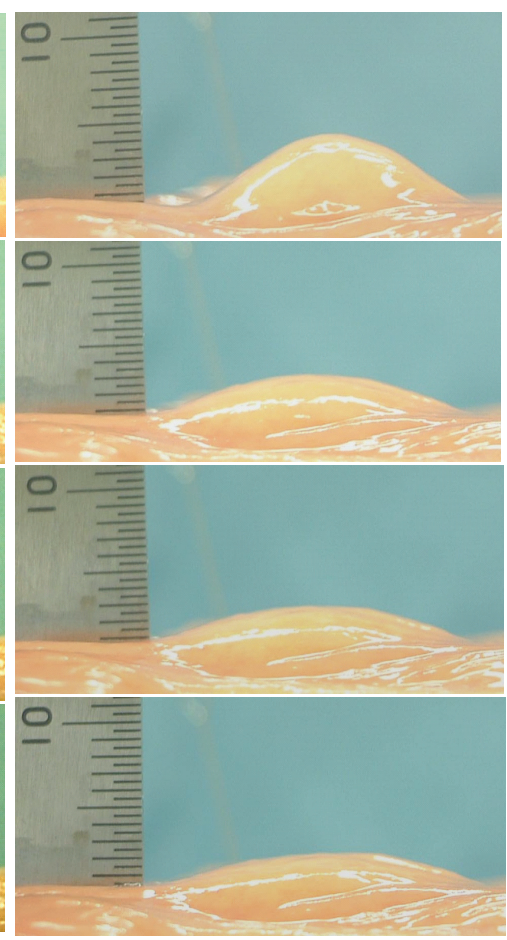

Figure 2 Changes in submucosal elevation immediately, and 3, 5, and 7 minutes after injection of glycerol and normal saline. The hemispheric shape produced by glycerol solution facilitated successful snaring (Sumiyoshi et al 2002). 
Table 2 Comparison of en-bloc resection rates based on lesion size (Uraoka et al 2005)

Total $\quad 10-19 \mathrm{~mm} \quad 20-29 \mathrm{~mm}$

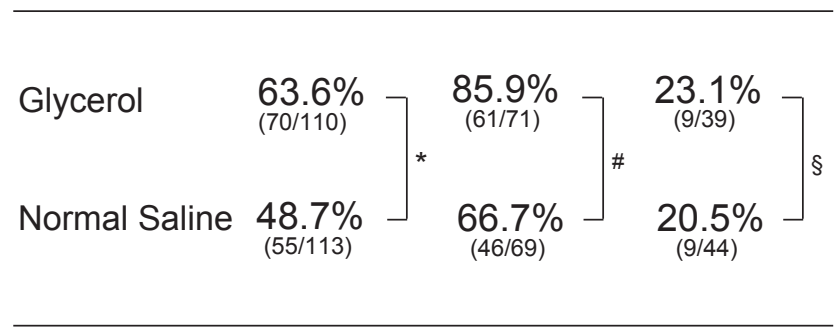

Notes: ${ }^{*} p=0.03 ;{ }^{\#} p<0.01 ; \S p=0.79$.

DW with concentrations $\geq 20 \%$ is not recommended due to the likelihood of histopathological tissue damage.

\section{Hyaluronic acid}

Hyaluronic acid (HA) is a type of glycosaminoglycan found in connective tissue. It has a high viscosity and water retention capability without being antigenic or toxic to humans (Nagano et al 1984). Approved indications for its use in clinical practice in many countries are for intra-articular injections for osteoarthritis and eye surgery. Recently, a $0.4 \%$ solution of HA has been approved for commercial use as a submucosal solution (MucoUp ${ }^{\circledR}$, Johnson and Johnson Medical Co., Tokyo, Japan) in Japan. HA has provided the longest-lasting fluid cushion (Yamamoto et al 1999, 2002, 2003; Fujishiro et al 2006), and higher successful en-bloc resection and lower perforation complication rates have been reported using HA, particularly for colorectal ESD (Yamamoto et al 2003; Saito et al 2005, 2007; Fujishiro et al 2006; Uraoka et al 2007). HA is considered to be the best agent for submucosal injections; however, its disadvantages are high cost (US $\$ 49.50-128.00 / \mathrm{mL}$ in the United States) and unavailability. In addition, the lack of Food and Drug Administration approval has limited its use in the United States, and stimulation in the growth of residual tumor cells has been indicated due to an enhancement in both tumor growth and CD44 expression of cancer cells at wound sites in murine models (Matsui et al 2004). HA is considered to be suitable, therefore, for ESD because of its higher en-bloc resection rate even for larger lesions, but not for endoscopic piecemeal resection procedures that have an increased risk of residual tumors.

\section{Hyaluronic acid mixture}

Fujishiro and colleagues (2004) investigated the possibility of a suitable lower-cost HA solution by varying the molecular weight of HA and mixing it with various solutions. The viscoelastic properties of HA can be changed using different molecules and mixing it with other solutions. Based on their results, a mixture of higher-molecular-weight HA and a sugar solution with or without glycerin is regarded as a more cost-effective submucosal fluid cushion option than conventional HA.

In further considering the issue of histopathological tissue damage, a mixture of HA and glycerol was found to be a better solution than a mixture of HA and DW, and there are, in fact, many reports of its use in colorectal ESDs (Saito et al 2005, 2007; Fujishiro et al 2006; Uraoka et al 2007).

\section{Fibrinogen mixture}

Fibrinogen mixture (FM) solution has a high viscosity and produces a long-lasting submucosal elevation (Lee et al 2004). It also helps keep the visual field clear after EMR by providing a microvascular hemostatic effect. Lee and colleagues (2006) conducted a prospective randomized study of the efficacy of FM compared with NS solution in conventional gastric EMRs after their preliminary examination confirmed the initial efficacy and safety of this solution (Lee et al 2004). Although there were no differences in en-bloc and complete resection rates, FM resulted in fewer injections and shorter procedure times. Subsequently, it has been primarily used in the ESD of larger lesions in Korea because of the longer-lasting submucosal fluid cushion, clear visual field after EMR, and reasonable cost (US $\$ 0.2 / \mathrm{mL}$ ) (Lee et al 2006).

Because fibrinogen is produced by the fractionalization of coagulation proteins in human serum, contamination with hepatitis or other viruses is possible; the risk of transmission of such viruses could pose a problem. If this issue can be resolved, however, FM could become a very useful solution in performing EMRs and ESDs due to its reasonable cost compared with other viscous agents, in addition to its hemostatic capability.

\section{Hydroxypropyl methylcellulose}

Hydroxypropyl methylcellulose (HPMC), a cellulose derivative with viscoelastic properties, is primarily used by ophthalmologists in Western countries for creating artificial tears (Ravalico et al 1997). It is also known to be stable when coming in contact with blood or a catheter at room temperature. A preliminary study on living porcine esophagus performed by a group in Rochester, Minnesota, showed long-lasting submucosal fluid cushion with minimal tissue reaction (Feitoza et al 2003). In another group study, 
NS, 0.1\% HA, 0.3\% HPMC, 2\% FM, and 20\% mannitol were compared for their submucosal elevation durations as well as the physical and chemical properties of each solution using a fresh transverse colon specimen from a mongrel model (Jin Hyun et al 2006). The submucosal elevation lasted longer with HA, HPMC, and FM than with mannitol or NS. Subsequently, the same Minnesota group successfully performed a novel EMR technique using HPMC for the removal of large areas of mucosa in pig models (Rajan et al 2004).

HPMC is less expensive than HA $(0.83 \%$ HPMC costs US $\$ 0.15 / \mathrm{mL}$ as a generic product in the United States) and is readily available in the United States. The major difference between the two solutions is that HA exists in the connective tissue of mammals and is not antigenic while HPMC is a synthetic product that could potentially give rise to antigenic reactions (Fujishiro et al 2004). More detailed toxicity testing in appropriate animal models will be necessary, therefore, before HPMC is ready to be used for medical applications on patients.

\section{Carboxymethylcellulose}

Carboxymethylcellulose (CMC) is used in the food science and pharmaceutical industries as a viscosity modifier or thickener. It has high viscosity and is reported to be nontoxic and generally nonallergenic (Fredericks et al 1986). An in vitro study in which a submucosal fluid cushion was created by injection of CMC solution using porcine stomach specimens (Burns et al 1997) demonstrated that it was possible to dissect the submucosal layer from the muscular layer as a result of higher viscosity at a CMC solution concentration greater than $2.0 \%$. Subsequently, submucosal injection of a $2.5 \% \mathrm{CMC}$ solution was assessed to be satisfactory for use, as ESD procedures in living pig models resulted in en-bloc resections of three specimens without any procedure-related complications. In addition, histopathological examinations revealed no tissue damage of the muscular layer and surrounding mucosal tissue. Because a CMC solution with a concentration greater than $2 \%$ is very viscous, a special $18 \mathrm{G}$ submucosal injection needle catheter was required to minimize injection resistance, as was a special hood attachment with a Teflon tube to insert the larger needle catheter. As with HPMC, further study on the safety and efficacy of $\mathrm{CMC}$ is necessary before it can be used on patients.

\section{Photocrosslinkable chitosan hydrogel in medium}

Chitosan (a natural polysaccharide produced by deacetylation of chitotin) hydrogel $(\mathrm{CH})$ solution is very viscous, has both hemostatic and anti-bacterial properties, and accelerates healing (Ono et al 2000; Ishihara et al 2001). In animal experiments with rat models (Ishizuka et al 2007), submucosal injection of $\mathrm{CH}$ produced a significantly thicker submucosal layer just after injection and reduced delayed bleeding in mucosal resections compared with hypertonic saline and HA. In addition, no cytotoxicity was revealed during in vitro testing using $\mathrm{CH}$ in human skin fibroblast, and endothelial and smooth muscle cells, but there is not yet enough reported evidence on the safety of $\mathrm{CH}$ when injected into the human body. More detailed toxicity testing in appropriate animal models will be necessary prior to actual clinical use.

\section{Injection solution with epinephrine}

Immediate and delayed bleeding are the most frequent complications associated with endoscopic resections. Because the incidence of colorectal polypectomy bleeding reportedly ranges from $0.3 \%$ to $6.1 \%$ (Rosen et al 1993 ; Winawer et al 1993; Gibbs et al 1996; Thiis-Evensen et al 1999; Citarda et al 2001), local epinephrine has been used to minimize mucosal bleeding due to its hemostatic effect, but the clinical benefit is unclear. One retrospective study (Folwaczny et al 1997) reported that submucosal injection of dilute epinephrine appeared to offer a distinct advantage over the injection of only saline in preventing delayed colorectal polypectomy bleeding. Two prospective randomized comparative studies of submucosal injections with and without epinephrine in colorectal polypectomies (Hsieh et al 2001; Lee et al 2007), however, reported contrasting clinical outcomes, as epinephrine in the submucosal injection fluid did not reduce the overall risk of delayed bleeding in either study. Immediate bleeding did occur less frequently in the epinephrine group than in the control group without epinephrine in one study (Hsieh et al 2001). However, immediate bleeding is generally not as serious as delayed bleeding because it can usually be successfully controlled using the endo-clip technique or electric coagulation methods such as hot biopsy or argon plasma coagulation (Parra-Blanco et al 2000; Tanaka et al 2001; Uraoka et al 2005). Therefore, we do not use local epinephrine despite its microvascular hemostatic effect during EMR procedures, but it cannot be avoided in ESDs particularly during submucosal cutting, as concomitant vasoconstrictive agent administration may be necessary (Soetikno et al 2003; Fujishiro et al 2006); however, clinical evidence is limited as to the efficacy of a dilute epinephrine mixture to reduce immediate bleeding. 


\section{Addition of dye to submucosal injection solution}

A small account of indigo carmine dye can be added to the submucosal injection solution during the ESD procedure to clarify the area of submucosal injection and to distinguish clearly between the muscle layer and the submucosal layer.

\section{Summary}

The "ideal" submucosal injection solution should provide a sufficiently high submucosal fluid cushion for safe and effective EMRs and ESDs while also preserving specimen tissue for accurate histopathological lesion assessment. The various agents differ in terms of effectiveness, cost, and availability, so that the appropriate submucosal injection solution should be chosen on a case-by-case basis taking into account the location and size of the lesion, the type of procedure (EMR or ESD) to be performed, and the kind of electrosurgical knife being used during the procedure.

For instance, glycerol is now a recommended solution because it facilitates easier and safer colorectal EMRs. HA has proven to be advantageous in performing gastric ESDs using a standard needle knife (Yamamoto et al 1999, 2002, 2003), but its use may not continue for EMRs and ESDs given its high cost. In fact, both glycerol and NS have been reported to be satisfactory when performing gastric ESDs with an insulationtipped (IT) knife (Ohkuwa et al 2001; Ono et al 2001; Soetikno et al 2003; Gotoda 2005).While HA is currently indispensable for reducing the risk of perforation in the narrow angulated and thinner wall of the colorectum, we have recently been using a more cost-effective mixture of HA and glycerol in colorectal ESDs (Saito et al 2005, 2007; Uraoka et al 2007).

Finally, several high viscosity solutions, including HPMC, $\mathrm{CMC}$, and $\mathrm{CH}$, have shown promising preliminary results, but more detailed toxicity testing is needed on appropriate animal models and humans before any of them will be ready for use in clinical endoscopic applications.

\section{Conclusion}

Safe and effective EMRs and ESDs require the selection of a facilitative submucosal injection solution that also takes into account relevant cost-benefit considerations. It should be noted, though, that successful endoscopy procedures also depend, in large part, on the skillful use of appropriate endoscopic techniques and devices.

\section{Disclosure}

The authors report no conflicts of interest in this work.

\section{References}

Burns JW, Colt MJ, Burgees LS, et al. 1997. Preclinical evaluation of Seprafilm bioresorbable membrane. Eur J Surg Suppl, 577:40-8.

Citarda F, Tomaselli G, Capocaccia R, et al. 2001. Efficacy in standard clinical practice of colonoscopic polypectomy in reducing colorectal cancer incidence. Gut, 48:812-15.

Conio M, Rajan E, Sorbi D, et al. 2002. Comparative performance in the porcine esophagus of different solutions used for submucosal injection. Gastrointest Endosc, 56:513-16.

Feitoza AB, Gostout CJ, Burgart LJ, et al. 2003. Hydroxypropyl methylcellulose: A better submucosal fluid cushion for endoscopic mucosal resection. Gastrointest Endosc, 57:41-7.

Folwaczny C, Heldwein W, Obermaier G, et al. 1997. Influence of prophylactic local administration of epinephrine on bleeding complications after polypectomy. Endoscopy, 29:31-33.

Fredericks CM, Kotry I, Holtz G, et al. 1986. Adhesion prevention in the rabbit with sodium carboxymethylcellulose solutions. Am J Obstet Gynecol, 155:667-70.

Fujishiro M, Yahagi N, Kashimura K, et al. 2004. Comparison of various submucosal injection solutions for maintaining mucosal elevation during endoscopic mucosal resection. Endoscopy, 36:579-83.

Fujishiro M, Yahagi N, Kashimura K, et al. 2004. Different mixtures of sodium hyaluronate and their ability to create submucosal fluid cushions for endoscopic mucosal resection. Endoscopy, 36:584-9.

Fujishiro M, Yahagi N, Kashimura K, et al. 2005. Tissue damage of different submucosal injection solutions for EMR. Gastrointest Endosc, 62:933-42.

Fujishiro M, Yahagi N, Nakamura M, et al. 2006. Successful outcomes of a novel endoscopic treatment for GI tumors: endoscopic submucosal dissection with a mixture of high-molecular-weight hyaluronic acid, glycerin, and sugar. Gastrointest Endosc, 63:243-9.

Gibbs DH, Opelka FG, Beck DE, et al. 1996. Postpolypectomy colonic hemorrhage. Dis Colon Rectum, 39:806-10.

Gotoda T. 2005. A large endoscopic resection by endoscopic submucosal dissection procedure for early gastric cancer. Clin Gastroenterol Hepatol, 3:S71-3.

Hsieh YH, Lin HJ, Tseng GY, et al. 2001. Is submucosal epinephrine injection necessary before polypectomy? A prospective, comparative study. Hepatogastroenterology, 48:1379-82.

Inoue H, Takeshita K, Hori H, et al. 1993. Endoscopic mucosal resection with a cap-fitted panendoscope for esophagus, stomach, and colon mucosal lesions. Gastrointest Endosc, 39:58-62.

Ishihara M, Ono K, Sato M, et al. 2001. Acceleration of wound contraction and healing with a photocrosslinkable chitosan hydrogel. Wound Repair Regen, 9:513-21.

Ishizuka T, Hayashi T, Ishihara M, et al. 2007. Submucosal injection, for endoscopic mucosal resection, of photocrosslinkable chitosan hydrogel in DMEM/F12 medium. Endoscopy, 39:428-33.

Jin Hyun J, Rae Chun H, Jai Chun H, et al. 2006. Comparison of the characteristics of submucosal injection solutions used in endoscopic mucosal resection. Scand J Gastroenterol, 4:488-92.

Karita M, Tada M, Okita K, et al. 1991. Endoscopic therapy for early colon cancer: the strip biopsy resection technique. Gastrointest Endosc, 37:128-32.

Katsinelos P, Kountouras J, Paroutoglou G, et al. 2006. Endoscopic mucosal resection of large sessile colorectal polyps with submucosal injection of hypertonic 50 percent dextrose-epinephrine solution. Dis Colon Rectum, 49:1384-92.

Kudo S. 1993. Endoscopic mucosal resection of flat and depressed types of early colorectal cancer. Endoscopy, 25:455-61.

Lee SH, Chung IK, Kim SJ, et al. 2007. Comparison of postpolypectomy bleeding between epinephrine and saline submucosal injection for large colon polyps by conventional polypectomy: a prospective randomized, multicenter study. World J Gastroenterol, 13:2973-7.

Lee SH, Cho WY, Kim HJ, et al. 2004. A new method of EMR: submucosal injection of a fibrinogen mixture. Gastrointest Endosc, $59: 220-4$. 
Lee SH, Park JH, Park do H, et al. 2006. Clinical efficacy of EMR with submucosal injection of a fibrinogen mixture: a prospective randomized trial. Gastrointest Endosc, 64:691-6.

Matsui Y, Inomata M, Izumi K, et al. 2004. Hyaluronic acid stimulates tumor-cell proliferation at wound sites. Gastrointest Endosc, 60:539-43.

Matsuzaki K, Nagao S, Kawaguchi A, et al. 2003. Newly designed soft pre-looped cap for endoscopic mucosal resection of gastric lesions. Gastrointest Endosc, 57:242-6.

Nagano K, Goto S, Okabe R, et al. 1984. Acute toxicity test of sodium hyaluronate [in Japanese]. Pharmacol Ther, 12:5369-77.

Ohkuwa M, Hosokawa K, Boku N, et al. 2001. New endoscopic treatment for intramucosal gastric tumors using an insulated-tip diathermic knife. Endoscopy, 33:221-6.

Okano H, Tsuji H, Kodama T, et al. 1990. Effect of endoscopic sclerotherapy and propranolol on the blood flow of esophageal varices. Am J Gastroenterol, 85:30-3.

Ono H, Kondo H, Gotoda T, et al. 2001, Endoscopic mucosal resection for treatment of early gastric cancer. Gut, 48:225-9.

Ono K, Saito Y, Yura H, et al. 2000. Photocrosslinkable chitosan as a biological adhesive. J Biomed Mater Res, 49:289-295.

Parra-Blanco A, Kaminaga N, Kojima T, et al. 2000. Hemoclipping for postpolypectomy and postbiopsy colonic bleeding. Gastrointest Endosc, 5:37-41.

Rajan E, Gostout CJ, Feitoza AB, et al. 2004. Widespread EMR: a new technique for removal of large areas of mucosa. Gastrointest Endosc, 60:623-7.

Ravalico G, Tognetto D, Baccara F, et al. 1997. Corneal endothelial protection by different viscoelastics during phacoemulsification. J Cataract Refract Surg, 23:433-9.

Rosen L, Bub DS, Reed JF 3rd, et al. 1993. Hemorrhage following colonoscopic polypectomy. Dis Colon Rectum, 36:1126-31.

Saito Y, Emura F, Matsuda T, et al. 2005. A new sinker-assisted endoscopic submucosal dissection for colorectal cancer. Gastrointest Endosc, 62:297-301.

Saito Y, Fujii T, Kondo H, et al. 2001. Endoscopic treatment for laterally spreading tumors in the colon. Endoscopy, 33:682-6.

Saito Y, Uraoka T, Matsuda T, et al. 2007. A pilot study to assess safety and efficacy of carbon dioxide insufflation during colorectal endoscopic submucosal dissection under conscious sedation. Gastrointest Endosc, 66:966-73.

Sakamaki M, Igarashi H, Nishiyama Y, et al. 2003. Effect of glycerol on ischemic cerebral edema assessed by magnetic resonance imaging. J Neurol Sci, 209:69-74.

Soetikno RM, Gotoda T, Nakanishi Y, et al. 2003. Endoscopic mucosal resection. Gastrointest Endosc, 57:567-79.

Sumiyoshi T, Fujii T, Sumiyoshi Y, et al. 2002. Injected substances to the submucosa in endoscopic mucosal resection: glycerin solution versus normal saline solution [abstract]. Gastrointest Endosc, 55:AB110.
Suzuki Y, Hiraishi H, Kanke K, et al. 1999. Treatment of gastric tumors by endoscopic mucosal resection with a ligating device. Gastrointest Endosc, 49:192-9.

Tanaka S, Haruma K, Oka S, et al. 2001. Clinicopathologic features and endoscopic treatment of superficially spreading colorectal neoplasms larger than $20 \mathrm{~mm}$. Gastrointest Endosc, 54:62-6.

Tada M, Murakami A, Karita M, et al. 1993. Endoscopic resection of early gastric cancer. Endoscopy, 25:445-50.

Takeuchi S, Koike T, Sasaki O, et al. 1989. Intracranial extradural pressure monitoring after direct operation on ruptured cerebral aneurysms. Neurosurgery, 24:878-83.

Taku K, Sano Y, Fu KI, et al. 2007. Iatrogenic perforation associated with therapeutic colonoscopy: a multicenter study in Japan. J Gastroenterol Hepatol, 22:1409-14.

Torii A, Sakai M, Kajiyama T, et al. 1995. Endoscopic aspiration mucosectomy as curative endoscopic surgery; analysis of 24 cases of early gastric cancer. Gastrointest Endosc, 42:475-9.

Uraoka T, Fujii T, Saito Y, et al. 2005. Effectiveness of glycerol as a submucosal injection for EMR. Gastrointest Endosc, 61:736-40.

Uraoka T, Kato J, Ishikawa S, et al. 2007. Thin endoscope-assisted endoscopic submucosal dissection for large colorectal tumors (with videos). Gastrointest Endosc, 66:836-9.

Uraoka T, Saito Y, Matsuda T, et al. 2006. Endoscopic indications for endoscopic mucosal resection of laterally spreading tumours in the colorectum. Gut, 55:1592-7.

Thiis-Evensen E, Hoff GS, Sauar J, et al. 1999. Population-based surveillance by colonoscopy: effect on the incidence of colorectal cancer. Telemark Polyp Study I. Scand J Gastroenterol, 34:414-20.

Yamamoto H, Yube T, Isoda N, et al. 1999. A novel method of endoscopic mucosal resection using sodium hyaluronate. Gastrointest Endosc, 50:251-256.

Yamamoto H, Kawata H, Sunada K, et al. 2002. Success rate of curative endoscopic mucosal resection with circumferential mucosal incision assisted by submucosal injection of sodium hyaluronate. Gastrointest Endosc, 56:507-12.

Yamamoto H, Kawata H, Sunada K, et al. 2003. Successful en-bloc resection of large superficial tumors in the stomach and colon using sodium hyaluronate and small-caliber-tip transparent hood. Endoscopy, 35:690-4.

Yamasaki M, Kume K, Yoshikawa I, et al. 2006. A novel method of endoscopic submucosal dissection with blunt abrasion by submucosal injection of sodium carboxymethylcellulose: an animal preliminary study. Gastrointest Endosc, 64:958-65.

Yamano H, Matsushita H, Yamanaka K, et al. 2004. A study of physical efficacy of different snares for endoscopic mucosal resection. Digest Endosc, 16:S85-8.

Winawer SJ, Zauber AG, Ho MN, et al. 1993. Prevention of colorectal cancer by colonoscopic polypectomy. The National Polyp Study Workgroup. N Engl J Med, 329:1977-81. 